Canadian

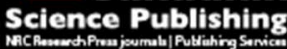

Applied Physiology, Nutrition, and Metabolism Physiologie appliquée, nutrition et métabolisme

\title{
Professor Bengt Saltin Symposium - Environmental Challenges to Human Performance
}

\begin{tabular}{|r|l|}
\hline Journal: & Applied Physiology, Nutrition, and Metabolism \\
\hline Manuscript ID & apnm-2016-0319.R1 \\
\hline Manuscript Type: & Symposium \\
\hline Date Submitted by the Author: & 08-Aug-2016 \\
\hline Complete List of Authors: & Ainslie, Philip; University of British Columbia, \\
\hline Keyword: & Bengt Saltin, exercise, high altitude physiology < physiology, temperature \\
\hline
\end{tabular}

\section{SCHOLARONE" \\ Manuscripts}




\title{
Professor Bengt Saltin Symposium - Environmental Challenges to Human Performance
}

Philip N. Ainslie

\author{
Invited Symposium Review
}

Centre for Heart, Lung and Vascular Health, School of Health and Exercise Sciences, University of British Columbia - Okanagan Campus, Kelowna, British Columbia, Canada

\section{Address for correspondence:}

Professor Philip N Ainslie

Centre for Heart, Lung and Vascular Health

School of Health and Exercise Sciences, Faculty of Health and Social Development, University of British Columbia, Okanagan Campus, Canada 3333 University Way

Kelowna, BC Canada V1V 1V7

Phone: 250 807-8089

Email: philip.ainslie@ubc.ca 


\section{Abstract}

This short review is from a presentation made at the Bengt Saltin Symposium, October 15-17, at the 2015 CSEP conference, Hamilton, Canada. The review provides context of the important work of the late Dr. Saltin's contributions to environmental physiology. In addition to well-controlled laboratory experiments to better understand the influence of hypoxia or temperature, or both, Dr. Saltin also led several field expeditions to the North Greenland, Kenya, Himalayas and the Andes, where he studied several aspects of human adaptation to environment. The 1998 Danish High-Altitude Expedition to the Andes, in particular, resulted in many major contributions to the field of altitude physiology including, but not limited to; mechanisms of reductions in maximal oxygen update; the lactate paradox; acclimatization; muscle metabolism; gas exchange, cerebrovascular physiology, etc. Of note, many of these related studies were conducted in both Danish sojourners to altitude and Bolivian altitude natives of Aymara ancestry, thus providing some of the most mechanistic comparisons with high altitude natives to date. A framework of these physiological contributions in terrestrial extremes is provided in this review.

Key words: Bengt Saltin, Exercise, High Altitude Physiology, Temperature 


\section{Introduction}

It is a great pleasure and privilege to provide an overview of the late Dr. Saltin's contributions to environmental physiology. Although Saltin's pioneering influence as a mentor and contributions to other areas of integrative physiology have been elegantly reviewed in a 157-page supplement published In the Scandinavian Journal of Medicine and Science in Sports in 2015, his impact in the broad field of environmental stress is equally as noteworthy. His early work conducted during his PhD studies (1959-64) while under the supervision of Per-Olof Astrand (Department of Physiology, University of Stockholm) is reported in detail in Acta Physiologica Scandinavica (Saltin, 1964). Upon reading this land-mark review paper (Saltin, 1964) - based on Saltin's PhD thesis which encompassed nine different experimental studies - in addition to the focus on how exercise and type of muscular work influenced maximal oxygen update, the importance of environmental stress in the context of muscular work and heat exposure with resultant dehydration were explored in characteristic detail and insight. Moreover, two sections in this review were based on field studies after prolonged 6-10 hour ski competitions. These field studies provided complementary information that would otherwise be impossible to duplicate in laboratory conditions. Perhaps it was this early experience of attempting to conduct sophisticated research in challenging conditions that motivated Saltin to continue the long-standing tradition of the earlier physiologists at the August Krogh Institute upon starting his 
faculty position in Denmark in 1973. Here, in addition to well-controlled laboratory experiments to better understand the influence of hypoxia or temperature, or both, Dr. Saltin also led several field expeditions to the North Greenland (Helge et al., 2003), Kenya (Saltin et al., 1995), Himalayas (Savard et al. 1995) and the Andes (Calbet et al., 2003, 2004, 2009; Lundby et al., 2006; Van hall et al., 2009), where he studied several aspects of human adaptation to environment.

This review provides a selected framework to some of Dr. Saltin's contributions that have markedly progressed our biological understanding of mechanisms and integrative physiology of operating in terrestrial extremes. Due to space constraints, not everything can be covered; therefore, without meaning to be disingenuous, particular focus is provided on Saltin's published contributions to thermal regulation and physiological adaption to hypoxia. Finally, Saltin's early insights into the now 'new' concept of environmental 'cross-adaptation' are summarized in this review.

\section{Thermal regulation.}

As mentioned, a large part of Saltin's early career examined the importance of environmental stress in the context of muscular work and heat exposure with resultant dehydration (Saltin, 1964a; Saltin, 1964b). In several studies he established how heat stress might limit exercise capacity was a tenant focus of this work; the fundamental relationships between muscle and core temperatures, 
metabolism, sweating rate, and dehydration were established (Saltin \& Hermansen, 1966; Saltin et al., 1968; Saltin et al., 1970; Saltin et al., 1972; Nadel et al., 1972; Savard at al., 1988; Nielsen et al., 1990). Related mechanism(s) of acclimation to the heat were published (Nielsen et al., 1993; Nielsen et al., 1997) establishing that it is the high core temperature per se, and not circulatory failure that underpins exhaustion during heat stressed exercise (Nielsen et al., 1993). Follow up studies provided evidence that elevated heat release in contracting skeletal muscle appears to be tightly coupled with changes in heat liberation (González-Alonso et al., 2000). The latter heat liberation is mediated during ATP production via the metabolic reactions involved early in exercise (GonzálezAlonso et al., 2000 \& 2001). Together, these studies not only informed our fundamental understanding of how heat stress impacts integrated physiological responses and capacity, but also provided mechanistic insight into how heat stress alters ATP production. The role of ATP was further established as an $\mathrm{O}_{2}$ sensor at the level of the erythrocyte in the regulation of skeletal muscle blood flow and $\mathrm{O}_{2}$ delivery (González-Alonso et al., 2002).

\section{Hypoxia.}

It has been well established that maximal work capacity is reduced during acute exposure to high altitude. Saltin was one of the first to establish that the cause of the reduction in maximal oxygen uptake was, in part, due to a limitation of oxygen transport at the alveolar-capillary membrane (Blomqvist, et al. 1969), 
and that the decrease in aerobic power can be offset by restoring a normal oxygen tension (Saltin et al. 1968). Related follow-up studies provided evidence that even moderate hyperoxia produced by increased ambient air pressure enhances the circulatory transport of oxygen in maximal exercise (Fagraeus et al. 1973), and that the working muscles have an aerobic potential exceeding what the circulation can normally offer (Fagraeus et al. 1973). Some of these early studies helped generated the notion that a combination of exercise training with an altitude (or hypoxic) condition may improve $\mathrm{VO}_{2}$ max and performance more effectively than exercise alone (Adams et al 1975, Faulkner et al. 1967, Hostman et al. 1980, Saltin et al. 1966, Saltin et al. 1968). The impact of altitude on anaerobic capacity was also explored (Saltin et al. 1967), and revealed that altitude exposure may result in a detraining response. These early studies seemed to be paramount in a series of follow-up studies, both in the laboratory and field, which sought to successfully determine the mechanism(s) that explain the changes and reductions in $\mathrm{VO}_{2}$ max during normobaric and hypobaric hypoxia (Calbet et al., 2003, 2004, 2009).

Acute hypoxia: As mentioned, it has been well established that, in acute normbaric hypoxia, maximal aerobic capacity is progressively reduced in close relationship to the reductions of inspired $\mathrm{PO}_{2}$ and related reductions in arterial oxygen content $\left(\mathrm{CaO}_{2}\right)$. Land-mark research established that changes in $\mathrm{CaO}_{2}$ induced by either breathing hypoxia, carbon monoxide, blood withdrawal or transfusion are compensated for by changes in cardiac output that ultimately 
result in maintenance of systemic $\mathrm{O}_{2}$ delivery during sub-maximal exercise (Asmussen \& Nielsen, 1946; Ekbolm et al., 1976). Specifically, at rest and during two-legged knee extension exercise, Satlin and his team employed isovolemic hemodiluation to reduce $\mathrm{CaO}_{2}($ and $\mathrm{Hb}$ ) via withdrawal of 1-1.5 liters of whole blood and concurrent replacement with albumin. This initial study revealed a low $\mathrm{CaO}_{2}$ induces an elevation in submaximal muscle blood flow and that $\mathrm{O}_{2}$ delivery to contracting muscles that is tightly regulated (Koskolou et al., 1997a, b). Elegant follow up studies demonstrated in humans that the regulation of cardiac output, leg blood flow, and $\mathrm{O}_{2}$ delivery to contracting skeletal muscle is dependent on signaling primarily from $\mathrm{CaO}_{2}$, not $\mathrm{PaO}_{2}$ (Roach et al., 1998). Over the next decade or so Saltin and his team further extended and explored the critical role - and related mechanisms - of $\mathrm{O}_{2}$ bound to hemoglobin in increasing skeletal muscle vasodilatation during exercise in humans (e.g., González-Alonso et al. 2001, etc.). These findings, as discussed in the next section, were also extended at high altitude (Calbet et al., 2002).

In a series of elegant experiments under the guidance of Saltin three main mechanisms, each explaining about one-third, of why $\mathrm{VO}_{2}$ max is reduced in hypoxia $\left(10.5 \% \mathrm{O}_{2}\right)$ was proposed (Calbet et al., 2003; Roach et al.., 1998; Calbet et al., 2009). These mechanisms included: 1) reductions in inspired $\mathrm{PO}_{2}$; 2) impairment in pulmonary gas exchange; and, 3) reductions of maximal cardiac output and peak leg blood flow (Calbet et al., 2003). It is relevant to note that these mechanisms are seemingly explicit to severe hypoxia (e.g., $\mathrm{PaO}_{2}$ 's $30-35$ ) 
and likely differ during more modest levels of hypoxemia (e.g., $\mathrm{PaO}_{2}$ 35-45 $\mathrm{mmHg}$ ). For example, during severe acute hypoxia, but not moderate hypoxia, maximal cardiac output was reduced to a greater extent - reductions that were mediated via reductions in both maximal stroke volume and heart rate (Calbet et al., 2009). Together, these findings explain why reductions in $\mathrm{VO}_{2}$ max are greater under conditions of severe acute hypoxia than could be explained by the fall in $\mathrm{SaO}_{2}$ and $\mathrm{CaO}_{2}$ (Fulco et al., 1998). Moreover, these studies stimulated and contributed to the controversial debate about the role of the CNS and the socalled 'Central Governor' model of fatigue (see: Noakes et al., 2004).

High altitude: As mentioned, Saltin led several field expeditions to study human adaptation to environmental stresses in to North Greenland(e.g., Helge et al., 2003), Kenya (e.g., Saltin et al., 1995), Himalayas (e.g., Savard et al. 1995) and the Andes (Saltin, 1967; Blomqvist et al. 1969; Savard et al. 1995). The pièce de résistance of these field studies was the 1998 Danish High-Altitude Expedition to the Andes. Here, the Danish researchers and volunteers conducted a series of experiments in Denmark before ascending to $5260 \mathrm{~m}$ at Mt Chacaltaya in Bolivia. The volunteers then spent 9 weeks at this high elevation and conducted some of the most detailed mechanistic research at high altitude to date. Overall, these elegant experiments resulted in many major contributions to the high altitude physiology field. For example, new insights were established in the acclimatization process and on mechanisms of reductions in maximal oxygen 
update (Calbet et al., 2003; Calbet et al., 2009), the lactate paradox (van Hall et al., 2001; van Hall et al., 2009), muscle metabolism (Lundby et al., 2006), gas exchange (Wagner et al., 2002), and cerebrovascular physiology (Iwasaki et al., 2011). Of note, many of these related studies were conducted at $4100 \mathrm{~m}$ in both Danish sojourners to altitude and Bolivian altitude natives of Aymara ancestry, thus providing some of the most mechanistic comparisons with natives to date. These experiments contained the Danish trademark of invasive experiments (e.g., femoral arterial and venous cannulations for the determination of limb blood flow via thermodiluation, indocyanine green for the assessment of cardiac output, blood volume manipulations, and various pharmacological blockades). To successfully conduct these extensive experiments in the field is an incredible achievement on many levels (Ainslie, 2004). A framework of these important physiological findings from the 1998 Danish High-Altitude Expedition to the Andes is provided next.

One of the fundamental questions that were addressed during the Chacaltaya expedition was why $\mathrm{VO}_{2}$ max and cardiac output is reduced at high altitude. Using invasive approaches, Saltin and his team established that two circulatory factors, independent of $\mathrm{O}_{2}$ transport to the muscle mitochondria, explain why $\mathrm{VO}_{2}$ max fails to recover following acclimatization: they are 1) failure of cardiac output to normalize; and 2) preferential redistribution of $Q$ to non-exercise tissues (Calbet et al. 2003). Related to the question of why $\mathrm{VO}_{2}$ max is reduced, studies on the same expedition addressed why heart rate is lower during exercise at 
altitude. Boushel and co-workers were able to show that the underlying mechanism is an enhanced parasympathetic neural activity (Boushel et al. 2001). This study was of great importance as it demonstrated that even when maximal heart rate at altitude is restored back to sea level values with a parasympathetic blockade, maximal cardiac output or stroke volume were not similarly enhanced. In other words, the reduction in maximal exercise heart rate at altitude is not the primary cause of the well-reported reductions in maximal cardiac output (Pugh et al., 1955; Saltin et al., 1968).

Concurrent studies on the Mt Chacaltaya expedition further explored that role of hemoglobin concentrations (Calbet et al., 2002) and plasma volume expansion on the regulation of cardiac output and $\mathrm{O}_{2}$ delivery during submaximal and maximal exercise. The first experiment, under conditions when $\mathrm{O}_{2}$ supply limits maximal exercise during large muscle mass exercise, established that elevations in hemoglobin do not improve exercise capacity, peak cardiac output or $\mathrm{VO}_{2}$ max; however, compensatory changes in leg blood flow were evident in response to the reductions in hemoglobin. These compensatory changes in leg blood flow as a result of the experimental hemodilution lead to similar peak $\mathrm{O} 2$ muscle delivery, such that there is an maintenance of maximal exercise capacity. These findings established that maximal cardiac output at altitude is not limited by a lower circulating volume or increased blood viscosity (Calbet et al., 2004). 
So, what is the main mechanism(s) explaining the reduction in $\mathrm{VO}_{2}$ max at altitude, especially when $\mathrm{CaO}_{2}$ is normalized via acclimatization? As outlined earlier, the Chacaltaya expedition demonstrated that two circulatory factors, independent of $\mathrm{O}_{2}$ transport to the muscle mitochondria, explain why $\mathrm{VO}_{2}$ max fails to recover following acclimatization (Calbet et al., 2002): 1) failure of cardiac output to normalize (via mechanisms related to reductions in stroke volume rather that heart rate per se; reviewed in Stembridge et al 2015); and 2) preferential redistribution of cardiac output to non-exercising tissues. Finally, it is important to note that these two factors pertain to a large exercising muscle mass under such conditions where $\mathrm{O}_{2}$ supply limits max exercise. When the exercise model allows preservation of $\mathrm{O}_{2}$ supply for engagement of small muscle mass (e.g., one legged knee extension to fatigue), similar exercise capacities to sea level are reported (Calbet et al., 2009). These findings are explained by a) reducing the size of the active muscle mass leading to an improvement in pulmonary gas exchange; b) attenuation of the Bohr effect on $\mathrm{O}_{2}$ unloading; and c) preservation of convection $\mathrm{O}_{2}$ transport to the active muscle to sea level values.

Although it is not possible to cover all aspects of Saltin and his teams' contributions to high altitude physiology, one last area that is of topical relevance to touch on is that of the controversy and so-called 'lactate paradox'. This paradox as been aptly defined (Kayser 1996) as 'In acclimatized humans at high altitude the reduction, compared to acute hypoxia, of the blood lactate 
concentration at any absolute VO2, as well as the reduction of maximal lactate accumulation after exhaustive exercise, compared to both acute hypoxia or normoxia, have been considered paradoxical; these phenomena have therefore become known as the lactate paradox'. Based on earlier observations by the Danes (Lundby et al., 2000) that the 'lactate paradox' is a transient metabolic phenomenon that is reversed during a prolonged period of exposure to severe hypoxia $(5400 \mathrm{~m})$ of more than 6 weeks, more detailed experiments were conducted as part of the prestigious Chacaltaya expedition (van Hall et al., 2009). Here, it was revealed that the net lactate release from the active leg was higher at $5260 \mathrm{~m}$ during chronic hypoxia compared to acute hypoxia at sea level. These findings imply an enhanced lactate utilization with prolonged acclimatization to altitude, and supports the absence of a lactate paradox in lowlanders sufficiently acclimatized to altitude.

Moreover, because of earlier reports that showed that high-altitude natives accumulate less lactate than normoxia lowlanders during incremental exhaustive exercise which was persistent after 6 weeks of de-acclimatization at sea level (termed 'the perpetual lactate paradox') (Hochachka, 1989), the Danes underwent follow up experiments in both low landers and high-altitude natives at sea level and after 2 and 8 weeks at $4100 \mathrm{~m}$ (El Alto, Bolivia). Again, the lactate paradox concept could not be demonstrated - and paradoxically - the highaltitude natives from the Andes actually exhibit a higher energy transfer, as evidenced by an greater muscle lactate accumulation, than lowlanders after 8 
weeks of acclimatization (van Hall et al., 2009). Debates for and against the evidence of the lactate paradox has been outlined (Wagner \& Lundby, 2007). As such controversy provides a catalyst for progression and this scientific debate is exemplary for moving science forward on this field.

\section{Cross-adaption.}

Physiological adaptation to environmental stressors is often studied in isolation, but these stressors are frequently combined outside of laboratory settings. Relevant examples include cold or heat and hypoxia. As recently highlighted (Lunt et al., 2010; Chauhan et al., 2015) especially in humans, there has been a paucity of research in this area. Thus, there is limited information about the effect that adaptation to one environment has on exposure to another thus forming a 'cross-adaptive' effect. It is relevant to note, however, that Saltin was exploring this 'new' concept of cross-adaptation as early as 1969 (Greenleaf et al., 1969) Moreover, the question of how environmental stress - whether it be heat, cold, hypoxia and/or prolonged exercise - impacted on integrative physiology and related metabolic adjustments was a long standing theme in Saltin's research. It is clear that he cherished conducting difficult and sophisticated research in challenging conditions.

In summary, the experimental complexities and related physiological integration of environmental challenges are clear. Few have made as great of an 
experimental impact on this field as Saltin. It was a true highlight and privilege to participate in the CSEP Saltin Symposium and write this short review on some of his contributions to environmental physiology. In view that Saltin's interests in environmental physiology likely accounts for $<5 \%$ of his better-known research contributions is a humbling statistic for many of us more junior researchers and provides perspective of the uniqueness of his career, talents and dedication.

\section{Conflict of interest: None}

\section{References:}

Adams WC, Bernauer EM, Dill DB, Bomar JB Jr. 1975. Effects of equivalent sea-level and altitude training on VO2max and running performance. J Appl Physiol. 39(2):262-6.

Ainslie PN. 2014. On the nature of research at high altitude: packing it all in! Exp Physiol. 99(5):741-2.

Asmussen E, Nielsen M. 1946. Studies on the regulation of respiration in heavy work. Acta Physiol Scand. 12:171-188

Blomqvist G, Johnson RL., Saltin B. 1969. Pulmonary diffusing capacity limiting human performance at altitude. Acta Physiol Scand. 76:284-287

Boushel R, Calbet JA, Rådegran G, Sondergaard H, Wagner PD, Saltin B. 2001. Parasympathetic neural activity accounts for the lowering of exercise heart rate at high 
altitude. Circulation. 9;104(15):1785-91.

Calbet JA, Boushel R, Radegran G, Sondergaard H, Wagner PD, Saltin B. 2003. Determinants of maximal oxygen uptake in severe acute hypoxia. Am J Physiol Regul Integr Comp Physiol. 2003a;284:R291-R303.

Calbet JA, Boushel R, Radegran G, Sondergaard H, Wagner PD, Saltin B. 2003. Why is VO2 max after altitude acclimatization still reduced despite normalization of arterial $\mathrm{O} 2$ content? Am J Physiol Regul Integr Comp Physiol. 284(2):R304-16.

Calbet JA, Rådegran G, Boushel R, Saltin B. 2009. On the mechanisms that limit oxygen uptake during exercise in acute and chronic hypoxia: role of muscle mass. J Physiol. Jan $15 ; 587(2): 477-90$

Calbet JA, Radegran G, Boushel R, Sondergaard H, Saltin B, Wagner PD. 2002. Effect of blood haemoglobin concentration on VO2 max and cardiovascular function in lowlanders acclimatised to 5260 m. J Physiol. 2002;545:715-728.

Calbet JA, Rådegran G, Boushel R, Søndergaard H, Saltin B, Wagner PD. 2004. Plasma volume expansion does not increase maximal cardiac output or VO2 max in lowlanders acclimatized to altitude. Am J Physiol Heart Circ Physiol. 87(3):H1214-24

Chauhan E, Bali A, Singh N, Jaggi AS. 2015. Cross stress adaptation: Phenomenon of interactions between homotypic and heterotypic stressors. Life Sci. 15;137:98-104.

Ekblom B, Wilson G, Astrand PO. 1976. Central circulation during exercise after 
venesection and reinfusion of red blood cells. J Appl Physiol.40:379-38

Fagraeus L, Karlsson J, Linnarsson D, Saltin B. 1973. Oxygen uptake during maximal work at lowered and raised ambient air pressures. Acta Physiol Scand. 87(3):411-21

Faulkner JA, Daniels JT, Balke B. 1967. Effects of training at moderate altitude on physical performance capacity. J Appl Physiol. 23(1):85-9.

Fulco CA, Rock PB, Cymerman A. 1998. Maximal and submaximal exercise performance at altitude. Aviat Space and Environ Med 69: 793-801.

Gonzalez-Alonso J, Richardson RS, Saltin B. 2001. Exercising skeletal muscle blood flow in humans responds to reduction in arterial oxyhaemoglobin, but not to altered free oxygen. J Physiol. 15;530(Pt 2):331-41

González-Alonso J, Olsen DB, Saltin B. 2002. Erythrocyte and the regulation of human skeletal muscle blood flow and oxygen delivery: role of circulating ATP. Circ Res. 29;91(11):1046-55.

González-Alonso J, Quistorff B, Krustrup P, Bangsbo J, Saltin B. 2000. Heat production in human skeletal muscle at the onset of intense dynamic exercise. J Physiol. 15;524 Pt 2:603-15.

Greenleaf JE, Greenleaf J, Card DH, Saltin B. 1969. Exercise-temperature regulation in man during acute exposure to simulated altitude. J Appl Physiol. 26(3):290-6. 
Helge JW, Lundby C, Christensen DL, Langfort J, Messonnier L, Zacho M, Andersen JL, Saltin B. 2003. Skiing across the Greenland icecap: divergent effects on limb muscle adaptations and substrate oxidation. J Exp Biol.206(Pt 6):1075-8

Hochachka PW. 1989. The lactate paradox: analysis of underlying mechanisms. Ann Sports Med 4, 184-188

Horstman D, Weiskopf R, Jackson RE. 1980. Work capacity during 3-wk sojourn at 4,300 m: effects of relative polycythemia. J Appl Physiol. 49(2):311-8.

Iwasaki K, Zhang R, Zuckerman JH, Ogawa Y, Hansen LH, Levine BD. 2011. Impaired dynamic cerebral autoregulation at extreme high altitude even after acclimatization. $\mathrm{J}$ Cereb Blood Flow Metab. 31(1):283-92.

Kayser B. 1996. Lactate during exercise at high altitude. Eur J Appl Physiol. 74, 195205

Koskolou MD, Calbet JA, Radegran G, Roach RC. 1997a. Hypoxia and the cardiovascular response to dynamic knee-extensor exercise. Am J Physiol Heart Circ Physiol. 272:H2655-H2663.

Koskolou MD, Roach RC, Calbet JA, Radegran G, Saltin B. 1997b. Cardiovascular responses to dynamic exercise with acute anemia in humans. Am J Physiol Heart Circ Physiol. 273:H1787-H1793. 
Lundby C, Saltin B, van Hall G. 2000. The 'lactate paradox', evidence for a transient change in the course of acclimatization to severe hypoxia in lowlanders. Acta Physiol Scand. 170(4):265-9.

Lundby C, Sander M, van Hall G, Saltin B, Calbet JA. 2006. Maximal exercise and muscle oxygen extraction in acclimatizing lowlanders and high altitude natives. $J$ Physiol. 1;573(Pt 2):535-4

Lunt HC, Barwood MJ, Corbett J, Tipton MJ. 2010. 'Cross-adaptation': habituation to short repeated cold-water immersions affects the response to acute hypoxia in humans. J Physiol. 15;588(Pt 18):3605-13.

Nadel ER, Bergh U, Saltin B. 1972. Body temperatures during negative work exercise. J Appl Physiol. 33(5):553-8

Nielsen B, Hales JR, Strange S, Christensen NJ, Warberg J, Saltin B. 1993. Human circulatory and thermoregulatory adaptations with heat acclimation and exercise in a hot, dry environment.J Physiol.;460:467-85

Nielsen B, Strange S, Christensen NJ, Warberg J, Saltin B. 1997. Acute and adaptive responses in humans to exercise in a warm, humid environment.

Pflugers Arch. 434(1):49-56

Nielsen B, Savard G, Richter EA, Hargreaves M, Saltin B 1990. Muscle blood flow and muscle metabolism during exercise and heat stress. J Appl Physiol. 69(3):1040-6. 
Noakes TD, Calbet JA, Boushel R, Søndergaard H, Rådegran G, Wagner PD, Saltin B. 2004. Central regulation of skeletal muscle recruitment explains the reduced maximal cardiac output during exercise in hypoxia. Am J Physiol Regul Integr Comp Physiol. 287(4):R996-9; author reply R999-1002.

Roach RC, Koskolou MD, Calbet JA, Saltin B. 1999. Arterial $\mathrm{O}_{2}$ content and tension in regulation of cardiac output and leg blood flow during exercise in humans. Am J Physiol Heart Circ Physiol. 276:H438-H445

Saltin B. 1967. Aerobic and anaerobic work capacity at 2300 meters. Med Thorac. 24(4):205-210.

Saltin B, Larsen H, Terrados N, Bangsbo J, Bak T, Kim CK, Svedenhag J, Rolf CJ. 1995. Aerobic exercise capacity at sea level and at altitude in Kenyan boys, junior and senior runners compared with Scandinavian runners. Scand J Med Sci Sports. 5(4):20921

Saltin B. 1964a. Aerobic work capacity and circulation at exercise in man with special reference to the effect of prolonged exercise and/or heat. Acta Physiol Scand Suppl. SUPPL 230:1-52

Saltin B. 1964b. Circulatory response to submaximal and maximal exercise after thermal dehydration. J Appl Physiol. 19:1125-32

Saltin B, Hermansen L. 1966. Esophageal, rectal, and muscle temperature during exercise. J Appl Physiol. 21(6):1757-62 
Saltin B, Gagge AP, Stolwijk JA. 1968. Muscle temperature during submaximal exercise in man. J Appl Physiol. 25(6):679-88

Saltin B, Gagge AP, Stolwijk JA. 1970. Body temperatures and sweating during thermal transients caused by exercise. J Appl Physiol. 28(3):318-27

Saltin B, Grover ER, Blomqvist CG, Hartley LH, Johnson RL. 1968. Maximal oxygen update and cardiac output after two weeks at 4300m. J Appl Physiol 25: 400-9.

$\underline{\text { Saltin B }}$, Gagge AP, Bergh U, Stolwijk JA. 1972. Body temperatures and sweating during exhaustive exercise. J Appl Physiol. 32(5):635-43.

Saltin B, Larsen H, Terrados N, Bangsbo J, Bak T, Kim CK, Svedenhag J. Rolf CJ. 1995. Aerobic exercise capacity at sea level and at altitude in Kenyan boys, junior and senior runners compared with Scandinavian runners. Scand J Med Sci Sports. 5:209221

Savard GK, Areskog NH, Saltin B. 1995. Cardiovascular response to exercise in humans following acclimatization to extreme altitude. Acta Physiol Scand. 154(4):499-509

Savard GK, Nielsen B, Laszczynska J, Larsen BE, Saltin B. 1985. Muscle blood flow is not reduced in humans during moderate exercise and heat stress. J Appl Physiol. $64(2): 649-57$

Stembridge M, Ainslie PN, Shave R. 2015. Mechanisms underlying reductions in stroke 
volume at rest and during exercise at high altitude. Eur J Sport Sci. 1:1-8

van Hall G, Calbet JA, Søndergaard H, Saltin B. 2001. The re-establishment of the normal blood lactate response to exercise in humans after prolonged acclimatization to altitude. J Physiol. 536(Pt 3):963-75

van Hall G, Lundby C, Araoz M, Calbet JA, Sander M, Saltin B. 2009. The lactate paradox revisited in lowlanders during acclimatization to $4100 \mathrm{~m}$ and in high-altitude natives. J Physiol. 587(Pt 5):1117-29

Wagner PD, Araoz M, Boushel R, Calbet JA, Jessen B, Rådegran G, Spielvogel H, Søndegaard H, Wagner H, Saltin B. 2002. Pulmonary gas exchange and acid-base state at $5,260 \mathrm{~m}$ in high-altitude Bolivians and acclimatized lowlanders. J Appl Physiol. 92(4):1393-400

Wagner PD, Lundby C. 2007. The lactate paradox: does acclimatization to high altitude affect blood lactate during exercise? Med Sci Sports Exerc. 39(5):749-55. 